\title{
Effects of Bilingualism on Reading Fluency: An Analysis of Pausing Patterns of Iranian Learners of English as a Third Language
}

\author{
Zahra Banitalebi, ${ }^{1}$ Ali Akbar Jabbari, ${ }^{1}$ Shouket Ahmad Tilwani, ${ }^{2}$ \\ and Mohammad Hasan Razmi ${ }^{1}{ }^{1}$ \\ ${ }^{1}$ Department of Foreign Languages, Yazd University, Yazd, Iran \\ ${ }^{2}$ Department of English, College of Science and Humanities, Prince Sattam Bin Abdulaziz University, \\ Al-Kharj 11942, Saudi Arabia \\ Correspondence should be addressed to Mohammad Hasan Razmi; hasanrazmi2000@gmail.com
}

Received 28 September 2021; Accepted 10 November 2021; Published 24 November 2021

Academic Editor: Syed Sameer Aga

Copyright ( $) 2021$ Zahra Banitalebi et al. This is an open access article distributed under the Creative Commons Attribution License, which permits unrestricted use, distribution, and reproduction in any medium, provided the original work is properly cited.

\begin{abstract}
Fluency is one of the most important components of oral proficiency, which can be affected by a number of variables including frequency, duration, and place of pause phenomena. The present study aimed at investigating the effect of bilingualism on learning a foreign language from the angle of fluency and pausing patterns by comparing the pausing patterns of monolingual (Persian speakers) and bilingual (Iranian Turkish speakers; L1: Turkish and L2: Persian) EFL learners. To this end, a sample of 40 male and female advanced EFL learners were selected from Yazd University and several English-language institutes. An English reading passage test was used to measure students' fluency in terms of their pausing patterns in prepared mode of speech. As learners started to read the passage, their speeches were recorded. The collected data were analyzed by Praat software. The statistical analyses revealed a significant difference between monolingual and bilingual learners in the frequency, duration, and placement of the pauses they had produced while they were reading the English passage. The results showed that bilingual learners outperformed monolingual participants, suggesting the superiority of bilinguals in their pausing patterns. The implications are discussed.
\end{abstract}

\section{Introduction}

For many years, researchers have investigated non-native learners under the cover term of second language learners. But more recently, a growing body of research has been conducted to distinguish between the two fields of L3 and L2 acquisitions $[1,2]$. Therefore, a number of studies have made a comparison between monolinguals and bilinguals in learning a foreign language [3-10].

One of the major challenges in research on trilingualism is finding an adequate definition of trilingualism itself. This is because, as with most cognitive and linguistic processes, trilingualism is an extremely complex phenomenon, one that may vary widely among individuals and even within individuals with respect to the languages concerned. Because of its complex nature and researchers' different points of view, definition for the term multilingualism has been a divergent one. According to McArthur and McArthur [11], multilingualism is the use of three or more languages either separately or in various degrees of mixing. Franceschini [12] defines it as the ability of societies, groups, institutions, and individuals to operate regularly in more than one language.

The same story is true of the definition of bilingualism. Generally, bilingualism is defined as "knowing" two languages [13]. The extent of "knowledge" is the native-like proficiency for some researchers, while some others see practicality enough. These definitions of bilingualism cannot distinguish between someone who may speak two languages, but only read and write in one (or none), as opposed to someone who may listen with understanding and reading in a language-what is termed "passive bilingualism"-but may not be able to speak or write in it [14]. The most explicit 
indicator of bilingualism is the degree of proficiency that an individual has in each language [15]. Although the key observable feature of language proficiency can be further compartmentalized into issues of fluency, it is not so straightforward how to measure levels of language proficiency. Therefore, the question persists as to the degree of fluency required of speakers in order to be classed as bilinguals.

Speech disfluency is a language performance phenomenon, which is not well understood by the language teaching profession, especially in the field of L3 in comparison with L2 acquisition [16]. Speech disfluencies are defined as phenomena interrupting the flow of speech without adding propositional contents to an utterance [17]. Based on the aforementioned definition, speech disfluencies contain all phenomena such as silent pauses, hesitations, repetitions, fillers, grammatical errors, mis-selected lexical items, selfcorrections, prolongations, false starts, slips of the tongue, and so on. Research on fluency has largely focused on temporal variables of L2 speech, namely, speech rate, repairs, amount and frequency of hesitation, location of pauses, and length of runs of fluent speech between pauses [18-23], among which pauses are regarded as one of the most important components. Pauses may be placed in expected positions such as at clause/phrase boundaries helping listeners to process messages or in unexpected positions which may reduce the smoothness of oral delivery. Like many others, for this study on fluency, a small selection of those variables is chosen, which are generally seen as the most salient. These are frequency, duration, and placement of pauses. The present study aims to investigate the effect of bilingualism on learning a foreign language from the angle of fluency and pausing patterns. So, this study compares pausing patterns of monolingual (Persian speakers) and bilingual (Iranian Turkish speakers; L1: Turkish and L2: Persian) EFL learners.

\section{Literature Review}

It was in the 1920s that bilingualism first attracted the attention of psychologists, when they became interested in understanding why bilinguals perform poorer at school than their monolingual peers [24]. Darcy [25], for example, concluded that "the general trend in the literature relating to the effect of bilingualism upon the measure of intelligence has been toward the conclusion that bilinguals suffer from a language handicap when measured by verbal tests of intelligence" (p.50).

Baker [26] argues that much of the early research led to invalid judgments by the inadequacy of present criteria such as deficiencies in testing, experimental design, statistical analysis, and sampling. Most of the bilinguals in many English-speaking countries such as Welshmen in Great Britain or Francophones in Canada were immigrants or inhabitants of economically backward rural regions, who were deprived of rigorous education, while their monolingual peers were from higher socioeconomic status regions. Therefore, completely ignoring these socioeconomic factors, early research would prove the disadvantage of being a bilingual [27].
Increasing concerns over the limitations of many of the underlying assumptions and methodological approaches used in early bilingual research led to a change in direction which was largely due to the work of Peal and Lambert in the 1960s. It was only with Peal and Lambert's [28] study that this prevalent negative picture of bilinguals' inferiority was reversed. In a comparison of a group of "balanced" (judged to be equivalent in their proficiency in both languages) French-Canadian children in Canada and a group of monolingual children (matched on background variables), bilinguals scored better than monolinguals on the majority of both verbal and nonverbal intelligence tests.

Although the evidence used against bilingual education is not convincing, there is still controversies among scholars, and the skeptical view about bilingual education may even go further and affect researchers' perspectives toward learning a third language on the whole. For example, Cenoz and Hoffmann [29] informed that the knowledge and the experience of the acquisition process of the two prior languages potentially affect that of a third language either positively or negatively, and not for sure positively. Clyne [30] even states that "the additional language complicates the operations of the processes" (p. 113).

Today, an abundance of studies on L3 learning has been conducted in different parts of the world (see [31] for a summary of studies in different places). Research on bilingualism sometimes presents perspicuous advantages for bilinguals over monolinguals. There are a number of scholars who believe in the superiority of multilinguals in language learning. For example, Afsharrad and Sadeghi Benis [3] compared 50 bilinguals with 36 monolinguals in Khorasan across gender for their strategy use and reading comprehension performance. The results of data analysis revealed that with regard to reading comprehension, bilinguals and females had better performance than monolinguals and males, respectively. They came to the conclusion that the better performance of bilinguals in reading ability might be mediated by their more effective use of metacognitive strategies. They explained the better performance of bilinguals in using metacognitive strategies by their experience with learning two languages, which improved their ability of planning and monitoring the process of L3 learning.

Additionally, Kassaian and Esmae'li [7] conducted research to explore the effect of bilingualism on third language breadth of vocabulary knowledge and word reading skill. Thirty female Armenian-Persian bilinguals and 30 female Persian monolinguals participated in this study. Nation's vocabulary levels test and the Burt word reading test, respectively, were used to measure subjects' knowledge of vocabulary and their word reading skill. After analyzing the data, they concluded that bilingualism was highly correlated with the breadth of vocabulary knowledge and reading skill.

Moreover, Dolgunsöz [6] (p. 17) summarized the cognitive, psychological, and cultural superiority of multilinguals derived from Paradowski [32]. Some of the cognitive superiorities are as follows: 
(i) Be better language learners in institutionalized learning contexts because of more developed language-learning capacities owing to the more complex linguistic knowledge and higher language awareness

(ii) Learn further languages more quickly and efficiently than their hitherto monolingual peers

(iii) Have increased ability to apply more reading strategies effectively due to their greater experience in language learning and reading in two or more different languages

(iv) Display generally greater cognitive flexibility, better problem-solving and higher-order thinking skills

Cook [33] referred to the advantages of multilingual people by addressing their unrestricted, expanded world views, which make other outlooks possible. Having a stereoscopic vision of the world from two or more perspectives, a multilingual person is able to be more flexible in thinking and learn reading more easily. Therefore, this could be seen as one of the main educational advantages of language teaching.

Segalowitz [34], who considers bilinguality in the framework of metalinguistic awareness, suggests that the bilinguals' incorporation of two languages will come about a more complex, better equipped "mental calculus" empowering the child to switch between two systems of rules in the manipulation of symbols.

Conducting an exploratory investigation of hesitation phenomena, Maclay and Osgood [35] came to the conclusion that hesitations fluctuate based on the dynamics of grammatical and lexical selections in spontaneous speech. In prepared mode of speech like reading, the printed text determines the content and structure of the sentence, and hence, any silent pauses would be expected to occur mainly for phonological and prosodic decision-making. On the one hand, while L2 learners have access to only one previously learned linguistic system, L3 learners have at least two background languages at their disposal that feed into L3 acquisition [36]. Therefore, L3 learners might be expected to have longer processing time during their speech production due to the knowledge of two other languages' syntax, semantics, and phonology. On the other hand, the acquisition of L3 can be affected by the fact that learners are more experienced as language learners and have developed their learning strategies and metalinguistic awareness to a greater extent. Here, a question arises that whether bilingualism could negatively or positively affect the pausing patterns of L3 learners in comparison with L2 learners.

To account for the lack of certainty and confidence regarding the aforementioned issues, the present study aimed to investigate the effect of bilingualism on learning a foreign language from the angle of fluency and pausing patterns. So, this study compared pausing patterns of monolingual (Persian speakers) and bilingual (Iranian Turkish speakers; L1: Turkish and L2: Persian) EFL learners.

In line with the objectives of the present study, the following questions were addressed in the current study:
(1) Do bilingual EFL learners differ from their monolingual counterparts in the frequency of the pauses produced when they are reading an English passage?

(2) Do bilingual EFL learners differ from their monolingual counterparts in the duration of the pauses produced when they are reading an English passage?

(3) Do bilingual EFL learners differ from their monolingual counterparts in the placement of the pauses produced when they are reading an English passage?

Accordingly, the following null hypotheses were formulated:

$\mathrm{H}_{01}$ : Bilingual EFL learners do not differ from their monolingual counterparts in the frequency of the pauses produced when they were reading an English passage.

$\mathrm{H}_{02}$ : Bilingual EFL learners do not differ from their monolingual counterparts in the duration of the pauses produced when they were reading an English passage. $\mathrm{H}_{03}$ : Bilingual EFL learners do not differ from their monolingual counterparts in the placement of the pauses produced when they were reading an English passage.

\section{Materials and Methods}

3.1. Participants. For the present study, the sample comprised 40 Iranian learners aged 22 to 40, both males and females. The participants were either M.A. or Ph.D. students at Yazd University, Shokouh, and Enekas institutes in Tehran. After explaining the objectives and procedures of the research to the aforementioned institutes, the researchers obtained the official approval to conduct the study and were provided the means to access the target sample. The study adopted convenient sampling to choose 40 learners among bilingual and multilingual EFL learners who agreed to take part in the study. The participants were informed about the aims of the study and consented to record their input. The APA ethical principles were considered closely throughout the study. The participants were divided into two groups based on their language backgrounds. The first group (i.e., half of the participants) was monolingual EFL learners. This group had only one language as their background, namely Persian, with which they were totally familiar. They were considered as L2 learners of English. The second group, consisted of the other half of participants, was bilingual EFL learners whose L1 was Turkish and their L2 was Persian. They were considered as L3 learners of English. It is worth mentioning that Persian is taught at school from age 7 onward. Moreover, English is added to the curriculum at age 13. However, Turkish is acquired naturally with no formal instruction. Since all the subjects of this group were M.A. or Ph.D. students, they enjoyed a long exposure to both Persian and Turkish languages.

3.2. Instruments. As mentioned earlier, the general objective of the present study was to discover the (possible) priority of bilingual learners over monolinguals in terms of their speech 
fluency by examining the pausing patterns adopted by Iranian Persian and Turkish EFL learners. To this end, two instruments that enabled the researcher to collect the required data were used. These instruments included: Oxford Quick Placement Test and a reading passage test (Appendix). The purpose of the placement test was to select the participants who were at advanced level (i.e., learners scored 48 to 60 ); and the reading passage test was used to measure students' fluency in terms of their pausing patterns. As speech fluency can be evaluated both through spontaneous (such as interview and conversation) and prepared speech (like reading), speakers' fluency in terms of the prepared mode of speech (i.e., reading) was taken into account in the present study to have more homogeneous data and avoid challenges of spontaneous speech. The passage was chosen from TOEFL iBT tests to measure students' fluency. As it is the most accepted English-language test in the world, the reliability and validity of this test have been already confirmed before.

3.3. Procedure. In the first step, the Oxford Quick Placement Test was administered to the participants to homogenize them in terms of their level of proficiency. After selecting 40 advanced learners, the passage test was conducted to determine the participants' pausing patterns. As learners started to read the passage, their productions were recorded. Then, the collected data were analyzed by Praat software [37]. In this regard, the frequency, duration, and placement of the participants' pauses were taken into account. A script for the identification of speaking time and pauses was created using Praat. This script was used to identify segments of silent pauses lasting longer than $250 \mathrm{~ms}$. Hesitations shorter than $250 \mathrm{~ms}$ were not relevant for this analysis, as they were not indicative of meaningful, planning pauses [38]. These intervals were measured on the spectrogram for each speech segment. The last step involved a comparison between pausing patterns of monolingual and bilingual learners.

3.4. Data Analysis. Data analysis procedures for this study comprised quantitative data analyses using Statistical Package for the Social Sciences (SPSS).

As to the inferential analyses, the researcher used a number of independent-samples $t$-tests to find out whether bilingualism affects learners' fluency in respect of frequency, duration, and placement of pauses they had produced reading the passage.

\section{Results}

4.1. Analysis of the Data on the First Research Question. The first research question was designed to investigate whether bilingual EFL learners differ from their monolingual counterparts in the frequency of the pauses they had produced reading the passage or not. To answer the research question, the researcher used relevant statistical procedures in SPSS. Table 1 shows the mean score of the two groups in terms of the frequency of pauses per minute. The mean score
Table 1: Descriptive Statistics of Participants' Pause Frequency in English per minute.

\begin{tabular}{lcccc}
\hline Participants & $N$ & Mean & Std. deviation & Std. error mean \\
\hline Monolinguals & 20 & 26.5200 & 0.44611 & 0.09975 \\
Bilinguals & 20 & 23.4970 & 0.34720 & 0.07764 \\
\hline
\end{tabular}

of the monolingual group was $26.52(\mathrm{SD}=.44)$, while the mean score of the bilingual group was $23.50(\mathrm{SD}=.34)$ with a mean difference of 3.02.

An independent-samples $t$-test was conducted to see if EFL learners of bilingual and monolingual groups differed on their performance on the frequency of pauses they had produced. An examination of the data indicated that there was no violation of the normality assumption. Levene's test for equality of variances further indicated the homogeneity of the variance $(p=.285)$. The results revealed that there was a significant difference between the subjects of the monolingual $(M=26.52, \quad \mathrm{SD}=.44)$ and bilingual groups $(M=23.50, \mathrm{SD}=.34)$. Table 2 shows that the column labeled Sig. (2-tailed) is .00, which is lower than 0.5. Therefore, the results obtained show that there was a statistically significant difference in the mean scores of the two groups $\left[t_{(38)}=23.915, p=0.285\right]$. The effect size for the independent-samples $t$-test was calculated showing a large effect size (eta squared $=0.93$ ).

\subsection{Analysis of the Data on the Second Research Question.} One of the objectives of the study was to deal with the difference between bilingual EFL learners and their monolingual counterparts in the duration of the pauses they had produced reading the passage test. Table 3 shows the mean score of the two groups in terms of the duration of pauses per minute. The mean score of the monolingual group was $13.38(\mathrm{SD}=0.34)$, while the mean score of the bilingual group was $10.49(\mathrm{SD}=0.39)$ with a mean difference of 2.89 .

An independent-samples $t$-test was conducted to see if the two groups differed on their performance on the duration of pauses they had produced. An examination of the data indicated that there was no violation of the normality assumption. Levene's test for equality of variances further indicated the homogeneity of the variance $(p=.67)$. The results revealed that there was a significant difference between the subjects of the monolingual group $(M=13.38$, $\mathrm{SD}=.34)$ and bilingual group $(M=10.49, \mathrm{SD}=.39)$. Table 4 shows the Sig. (2-tailed) of .00, which is lower than 0.5 . Hence, the results revealed that there was a statistically significant difference in the mean scores of the two groups $\left[t_{(38)}=24.719, p=.67\right]$. The effect size for the independentsamples $t$-test was calculated showing a large effect size (eta squared $=0.94)$.

\subsection{Analysis of the Data on the Third Research Question.} The third research question was designed to investigate whether bilingual EFL learners differ from their monolingual counterparts in the placement of the pauses they had produced when they were reading the passage or not. To 
TABLE 2: Results of independent-samples $t$-test for pause frequency in English.

\begin{tabular}{lcccccc}
\hline & \multicolumn{2}{c}{ Levene's test } & \multicolumn{3}{c}{$t$-test for equality of means } \\
& $F$ & Sig. & $t$ & Df & Sig. (2-tailed) & Mean difference \\
\hline Equal variances & 1.174 & 0.285 & 23.91 & 38 & 0.000 & 3.023 \\
Nonequal variances & & & 23.91 & 35.83 & 0.000 & 3.023 \\
\hline
\end{tabular}

TABLE 3: Descriptive statistics of participants' pause duration in English per minute.

\begin{tabular}{lcccc}
\hline Participants & $N$ & Mean & Std. deviation & Std. error mean \\
\hline Monolinguals & 20 & 13.3830 & 0.34360 & 0.07683 \\
Bilinguals & 20 & 10.4930 & 0.39409 & 0.08812 \\
\hline
\end{tabular}

answer the research question, the researcher compared the mean performance of mid-clause and end-clause pauses across the bilingual and monolingual subjects so as to explore whether the difference between groups in this study was statistically significant or not. Table 5 offers the descriptive results of the two groups in terms of the placement of pauses per minute. Considering mid-clause pauses on the one hand, the mean score of the monolingual group was $19.35(\mathrm{SD}=.73)$, while the mean score of the bilingual group was $16.67(\mathrm{SD}=.93)$ with a mean difference of 2.67. On the other hand, taking into account the end-clause pauses, the mean score of the monolingual group was $7.18(\mathrm{SD}=.97)$, while the mean score of the bilingual group was 6.78 $(\mathrm{SD}=1.01)$ with a mean difference of .40 .

An independent-samples $t$-test was conducted to see if bilingual and monolingual groups differed significantly on their performance on the placement of pauses they had produced (Table 6). An examination of the data indicated that there was no violation of the normality assumption. Levene's test for equality of variances further indicated the homogeneity of the variance $(p=0.04$ and 0.88$)$ was met. The results revealed that there was not a significant difference between the subjects of the monolingual $(M=7.18$, $S D=0.97)$ and bilingual group $(M=6.78, S D=1.01)$ in the production of end-clause pauses, but a significant difference between the subjects of the monolingual $(M=19.35$, $S D=0.73)$ and bilingual group $(M=16.67, S D=0.93)$ in the production of mid-clause pauses was found. The results obtained show that there was not a statistically significant difference in the mean performance of end-clause pauses of the two groups $\left[t_{(38)}=1.27, p=0.88\right]$ as the Sig. (2-tailed) is .210. The eta squared value was .04, suggesting a moderate effect size. However, due to the Sig. (2-tailed) of 0.00 , the difference in the mean performance of mid-clause pauses of the two groups was significant $\left[t_{(38)}=10.07, p=0.04\right]$ with a large effect size of 0.73 .

\section{Discussion}

The first research question of the study aimed to compare the monolingual and bilingual Iranian EFL learners in the frequency of pauses they had produced while they were reading the English passage. The obtained results suggested that, regardless of gender factor, multilingualism is a determining factor in the number of pauses produced. The statistical accounts showed that the difference in the mean score of the monolingual and bilingual learners was statistically significant. Therefore, in response to the first research question, it can be mentioned that there was a significant difference between monolingual and bilingual learners in the frequency of pauses produced. The results showed that the bilingual group outperformed the monolingual group in this regard. Furthermore, the first research null hypothesis, claiming no significant difference between monolingual and bilingual learners in the frequency of produced pauses, is rejected.

With respect to the second research question of the study, investigating the difference between monolingual and bilingual Iranian EFL learners in the duration of pauses they had produced reading the English passage, it can be mentioned that the obtained results suggested a significant difference in the mean scores of pause duration across the two groups. Comparison of the mean scores revealed that bilingual learners performed better than monolingual ones with a significant mean difference. Therefore, the second research null hypothesis, claiming no significant difference between monolingual and bilingual learners in the duration of produced pauses, is rejected.

The third research question sought to explore the difference between monolingual and bilingual Iranian EFL learners in the placement of pauses they had produced when they were reading the English passage. The results, using independent-samples $t$-tests, suggested that there was not a significant difference between the subjects of the monolingual and bilingual groups in the production of end-clause pauses, but a significant difference between the subjects of the monolingual and bilingual groups in the production of mid-clause pauses was found. Therefore, in response to the third research question, it can be mentioned that there was a significant difference between monolingual and bilingual learners in the placement of pauses produced. Although the two groups acted similarly in the production of end-clause pauses, the results showed that the bilingual group outperformed monolingual group in the production of midclause pauses. As fluent speakers place pauses in the expected positions such as clause/phrase boundaries and not in the unexpected positions like at the middle of the clause/ phrase, bilinguals acted more similarly to fluent speakers in this regard. Moreover, the third research null hypothesis, claiming no significant difference between monolingual and bilingual learners in the placement of produced pauses, is rejected. 
TABLE 4: Results of independent-samples $t$-test for pause duration in English.

\begin{tabular}{lcccccc}
\hline & \multicolumn{2}{c}{ Levene's test } & \multicolumn{3}{c}{$t$-test for equality of means } \\
& $F$ & Sig. & $t$ & $\mathrm{~d} f$ & Sig. (2-tailed) & Mean difference \\
\hline Equal variances & 0.175 & 0.678 & 24.71 & 38 & 0.000 & 2.89000 \\
Equal variances & & & 24.71 & 37.30 & 0.000 & 2.89000 \\
\hline
\end{tabular}

Table 5: Descriptive statistics of participants' pause placement in English.

\begin{tabular}{lccccc}
\hline & Participants & $N$ & Mean & Std. deviation & Std. error mean \\
\hline \multirow{2}{*}{ Mid_Clause } & Monolinguals & 20 & 19.3550 & 0.73168 & 0.16361 \\
& Bilinguals & 20 & 16.6770 & 0.93725 & 0.20958 \\
End_Clause & Monolinguals & 20 & 7.1860 & 0.97931 & 0.21898 \\
& Bilinguals & 20 & 6.7840 & 1.01429 & 0.22680 \\
\hline
\end{tabular}

TAвLE 6: Results of independent-samples $t$-test for pause placement in English.

\begin{tabular}{|c|c|c|c|c|c|c|c|}
\hline & & \multicolumn{2}{|c|}{ Levene's test } & \multicolumn{4}{|c|}{$T$-test for equality of means } \\
\hline & & $F$ & Sig. & $t$ & $\mathrm{~d} f$ & Sig. (2-tailed) & Mean difference \\
\hline \multirow{2}{*}{ Mid_Clause } & Equal variances & 4.325 & 0.044 & 10.072 & 38 & 0.000 & 2.67800 \\
\hline & Nonequal variances & & & 10.072 & 35.887 & 0.000 & 2.67800 \\
\hline \multirow{2}{*}{ End_Clause } & Equal variances & 0.023 & 0.880 & 1.275 & 38 & 0.210 & 0.40200 \\
\hline & Nonequal variances & & & 1.275 & 37.953 & 0.210 & 0.40200 \\
\hline
\end{tabular}

Upon closer inspection of the studies done on the relationship between bilingualism and language learning specifically fluency and pausing patterns, the results obtained so far are in line with most of the previous ones. While some studies show the superiority of bilinguals in different aspects of language learning $[3,5-7,9,10,39,40]$, others indicate no such relationship $[4,41,42]$ and not even a negative one. As a whole, a host of factors are involved in determining the direction of this relationship. A number of such factors include experimental design, sampling, socioeconomic status of participants, etc.

A study that may be of relevance is that of Afsharrad and Sadeghi Benis [3]. In a part of their study, they compared 50 bilinguals with 36 monolingual learners for their reading comprehension performance and metacognitive strategy use. The results showed that bilingual learners were more successful regarding their metacognitive strategy use and their reading comprehension. They explained that the better performance of bilinguals in reading ability might be mediated by their more effective use of metacognitive strategies. Although the variables under investigation in the present study were different from those of Afsharrad and Sadeghi Benis [3], the results of the two studies were similar in that the bilingual group outperformed monolingual one regarding their reading skills.

Concerning the type of the test used in this study, reading passage tests, which were aimed to measure prepared speech fluency, the study done by Kassaian and Esmae'li [7] may be of relevance here. As a part of their study, Kassaian and Esmae'li conducted a research to explore the effect of bilingualism on third-language word reading skill, and after analyzing the data, they concluded that bilingualism was highly correlated with reading skill.
In addition, by referring to unrestricted, expanded world views of multilinguals, Cook [33] stated that multilingual people are more flexible in their thinking and learn reading more easily. Therefore, corresponding to the results of the current study, Cook [33] also believed that multilinguals are better readers in comparison with bilinguals. Moreover, Paradowski [32], mentioning the cognitive superiorities of multilinguals, referred to multilinguals' increased ability to apply more reading strategies effectively and linked this quality to their greater experience in language learning and reading in two or more different languages [43].

The superiority of bilingual learners can also be attributed to their better equipped "mental calculus," which empowers the subjects to switch between two systems of rules in the manipulation of symbols [34].

\section{Conclusion}

This study attempted to investigate the impact of bilingualism on the production of pausing patterns by proficient Iranian EFL learners in general. The findings of this study provide further evidence for the superiority of bilingual learners in learning a foreign language in general and in production of pausing patterns specifically, which bring about some implications for teachers and syllabus designers to take into account the linguistic background of learners. They can clarify and explicate the components of fluency to language learners and design some drills to improve their fluency in speech production. By listening to the voices of the students, through needs analysis procedures, teachers and other responsible stakeholders can realize their needs and design more suitable syllabuses to offer more useful courses [44]. This study suffers from some limitations such as generalizability of the findings and limited sample size. 
The reason is obviously the lack of random sampling procedures because from a practical point of view, it was not possible for the researchers to recruit the participants randomly and they had to choose the participants based on a convenient sampling procedure by selecting those who were available to them. Therefore, further research on this topic is warranted. As another suggestion, the possible effect of gender, age, proficiency level, and language backgrounds can be taken into account to explore any possible new outcomes.

\section{Appendix}

\section{English Reading Passage Test}

Agriculture, Iron, and the Bantu People. There is evidence of agriculture in Africa prior to 3000 B.C. It may have developed independently, but many scholars believe that the spread of agriculture and iron throughout Africa linked it to the major centers of the Near East and Mediterranean world. The drying up of what is now the Sahara Desert had pushed many people to the south into sub-Saharan Africa. These people settled at first in scattered hunting-and-gathering bands, although in some places near lakes and rivers, people who fished with a more secure food supply lived in larger population concentrations. Agriculture seems to have reached these people from the Near East since the first domesticated crops were millet and sorghum whose origins are not African but West Asian. Once the idea of planting diffused, Africans began to develop their own crops such as certain varieties of rice, and they demonstrated a continued receptiveness to new imports. The proposed areas of the domestication of African crops lie in a band that extends from Ethiopia across southern Sudan to West Africa. Subsequently, other crops such as bananas were introduced from Southeast Asia.

Livestock also came from outside Africa. Cattle were introduced from Asia as probably were domestic sheep and goats. Horses were apparently introduced by the Hyksos invaders of Egypt (1780-1560 B.C.) and then spread across the Sudan to West Africa. Rock paintings in the Sahara indicate that horses and chariots were used to traverse the desert and that, by 300-200 B.C., there were trade routes across the Sahara. Horses were adopted by people of the West African Savannah and later their powerful cavalry forces allowed them to carve out large empires. Finally, the camel was introduced around the first century A.D. This was an important innovation because the camel's ability to thrive in harsh desert conditions and to carry large loads cheaply made it an effective and efficient means of transportation. The camel transformed the desert from a barrier into a still difficult, but more accessible route of trade and communication.

Iron came from West Asia, although its routes of diffusion were somewhat different from those of agriculture. Most of Africa presents a curious case in which societies moved directly from a technology of stone to iron without passing through the intermediate stage of copper or bronze metallurgy, although some early copper-working sites have been found in West Africa. Knowledge of iron making penetrated into the forests and Savannah of West Africa at roughly the same time that iron making was reaching Europe. Evidence of iron making has been found in Nigeria, Ghana, and Mali.

This technological shift caused profound changes in the complexity of African societies. Iron represented power. In West Africa, the blacksmith who made tools and weapons had an important place in society, often with special religious powers and functions. Iron hoes, which made the land more productive, and iron weapons, which made the warrior more powerful, had symbolic meaning in a number of West African societies. Those who knew the secrets of making iron gained ritual and sometimes political power.

Unlike in the America where metallurgy was a very late and limited development, Africans had iron from a relatively early date, developing ingenious furnaces to produce the high heat needed for production and to control the amount of air that reached the carbon and iron ore necessary for making iron. Much of Africa moved right into the Iron Age, taking the basic technology and adapting it to local conditions and resources.

The diffusion of agriculture and later of iron was accompanied by a great movement of people who may have carried these innovations. These people probably originated in eastern Nigeria. Their migration may have been set in motion by an increase in population caused by a movement of people fleeing the desiccation or drying up of the Sahara. They spoke a language, proto-Bantu ("bantu" means "the people"), which is the parent tongue of a large number of Bantu languages still spoken throughout sub-Saharan Africa. Why and how these people spread out into central and southern Africa remains a mystery, but archaeologists believe that their iron weapons allowed them to conquer their hunting-gathering opponents who still used stone implements. Still, the process is uncertain and peaceful migration-or simply rapid demographic growth-may have also caused the Bantu explosion.

\section{Data Availability}

The data are accessible through correspondence with the first author.

\section{Disclosure}

The authors confirm that the ideas expressed in the submitted article are their own and not those of an official position of the institution or funder.

\section{Conflicts of Interest}

The authors declare that they have no conflicts of interest.

\section{References}

[1] M. Jamali, A. A. Jabbari, and M. H. Razmi, "Acquisition of attributive adjectives and noun adjuncts by L3 learners of French and German: Further evidence for the Typological primacy model (TPM)," International Review of Applied Linguistics in Language Teaching, 2021. 
[2] F. Khezri, M. H. Razmi, A. A. Jabbari, and H. Ghadaki, "The acquisition of French (L3) prepositions by Iranian learners of English," Applied Linguistics Research Journal, vol. 4, no. 4, pp. 41-56, 2020.

[3] M. Afsharrad and A. R. Sadeghi Benis, "Differences between monolinguals and bilinguals/males and females in English reading comprehension and reading strategy use," International Journal of Bilingual Education and Bilingualism, vol. 20, no. 1, pp. 34-51, 2017.

[4] H. C. Barik and M. Swain, "Evaluation of a French immersion program: The Ottawa study through grade five," Canadian Journal of Behavioural Science/Revue Canadienne des Sciences du Comportement, vol. 10, no. 3, pp. 192-201, 1978.

[5] J. Cenoz, "Towards multilingual education: Basque educational research from an international perspective," in Bristol, Blue Ridge Summit: Multilingual Matters, University of Michigan, Ann Arbor, MI, USA, 2009.

[6] E. Dolgunsöz, "Benefits of multilingualism in foreign language learning: a comparative study of bilingual and multilingual grammar strategies," International Online Journal of Education and Teaching, vol. 1, no. 1, pp. 148-225, 2013.

[7] Z. Kassaian and S. Esmae'li, "The effect of bilinguality on L3 breadth of vocabulary knowledge and word reading skill," Theory \& Practice in Language Studies, vol. 1, no. 8, pp. 966-974, 2011.

[8] E. Namaziandost, M. H. Razmi, S. Heidari, and S. A. Tilwani, "A contrastive analysis of emotional terms in bed-night stories across two languages: does it affect learners' pragmatic knowledge of controlling emotions? Seeking implications to teach English to EFL learners," Journal of Psycholinguistic Research, vol. 50, no. 3, pp. 645-662, 2021.

[9] A. Seifi and S. Jalal Abdolmanafi Rokni, "Do intermediate monolinguals and bilinguals use different learning strategies?" International Journal of English Language Education, vol. 2, no. 1, pp. 57-70, 2013.

[10] J. Thomas, "The role played by metalinguistic awareness in second and third language learning," Journal of Multilingual and Multicultural Development, vol. 9, no. 3, pp. 235-246, 1988.

[11] T. B. McArthur and F. McArthur, The Oxford Companion to the English Language, Oxford University Press, Oxford, England, 1992.

[12] R. Franceschini, "The genesis and development of research in multilingualism," in AILA Applied Linguistics Series, The Exploration of Multilingualism, vol. 6, pp. 27-60, John Benjamin publishing, Amsterdam, The Netherlands, 2009.

[13] G. Valdez and R. A. Figueora, Bilingual and Testing: A Special Case of Bias, Ablex Publishing Corporation, Norwood, NJ, USA, 1994.

[14] S. Ziashahabi, A. A. Jabbari, and M. H. Razmi, "The effect of interventionist instructions of English conversational implicatures on Iranian EFL intermediate level learners' pragmatic competence development," Cogent Education, vol. 7, no. 1, pp. 1-21, 2020.

[15] E. Namaziandost, M. H. Razmi, A. Atabekova, T. Shoustikova, and B. H. Kussanova, "An account of Iranian intermediate EFL learners' vocabulary retention and recall through spaced and massed distribution instructions," Journal of Education, 2021.

[16] Z. Banitalebi, A. A. Jabbari, and M. H. Razmi, "Cross-linguistic gender differences in EFL learners' pause frequency and duration," Iranian Journal of Learning and Memory, vol. 3, no. 9, pp. 19-27, 2020.
[17] K. Menyhárt, "Age-dependent types and frequency of disfluencies," in Tutorial and Research Workshop on Disfluency in Spontaneous Speech: Gothenburg Papers in Theoretical Linguistics, pp. 45-48, Göteborg University, Sweden, Europe, 2003.

[18] B. F. Freed, Second Language Acquisition in a Study Abroad Context, John Benjamins, Amsterdam, Netherlands, 1995.

[19] L. Hansen, J. Gardner, and J. Pollard, "The measurement of fluency in a second language: Evidence from the acquisition and attrition of Japanese," On JALT, vol. 97, pp. 37-45, 1998.

[20] P. Lennon, "Investigating fluency in EFL: a quantitative approach," Language Learning, vol. 40, no. 3, pp. 387-417, 1990.

[21] D. A. Möhle, "Comparison of the second language speech production of different native speakers," in Second Language Production, pp. 26-49, Tubingen University, Tubingen, Germany, 1984.

[22] M. Raupach, "Analysis and evaluation of communicative strategies," in Strategies in Interlanguage Communication, pp. 199-201, Longman, London, UK, 1983.

[23] H. Riggenbach, "Toward an understanding of fluency: a microanalysis of nonnative speaker conversations," Discourse Processes, vol. 14, no. 4, pp. 423-441, 1991.

[24] S. May, H. Hill, and S. Tiakiwai, Bilingual/immersion Education: Indicators of Good Practice: Final Report to the Ministry of Education, Ministry of Education, Wellington, New Zealand, 2004, http://www.kns.ac.nz/files/6d9cf62d1d8e8824/ file_set_file/0000/0532/May,\%20Hill,\%20Tiakiwai\% 20(2004)\%20Education\%20Counts.pdf.

[25] N. T. Darcy, "A review of the literature on the effects of bilingualism upon the measurement of intelligence," The Pedagogical Seminary and Journal of Genetic Psychology, vol. 82, no. 1, pp. 21-57, 1953.

[26] C. Baker, Foundations of Bilingual Education and Bilingualism, Multilingual Matters, UK, Bristol, 3rd edition, 2001.

[27] Z. Wodniecka and N. J. Cepeda, "Beyond the classroom: Bilingualism, cognitive skills, and health," Mosaic, vol. 9, no. 3, pp. 3-8, 2007.

[28] E. Peal and W. E. Lambert, "The relation of bilingualism to intelligence," Psychological Monographs: General and Applied, vol. 76, no. 27, pp. 1-23, 1962.

[29] J. Cenoz and C. Hoffmann, "Acquiring a third language: what role does bilingualism play?” International Journal of Bilingualism, vol. 7, no. 1, pp. 1-5, 2003.

[30] M. Clyne, "Some of the things trilinguals do," International Journal of Bilingualism, vol. 1, no. 2, pp. 95-116, 1997.

[31] J. Cenoz, "The additive effect of bilingualism on third language acquisition: a review," International Journal of Bilingualism, vol. 7, no. 1, pp. 71-87, 2003.

[32] M. B. Paradowski, "The benefits of multilingualism," Multilingual Living Magazine, vol. 3, no. 2, pp. 18-20, 2010.

[33] V. J. Cook, "Requirements for a multilingual model of language production," Asian EFL Journal/Professional Teaching Articles, vol. 7, no. 86, pp. 45-64, 2001.

[34] N. Segalowitz, Psychological Perspectives on Bilingual Education, Sir George Williams University, Psychology Department, Montreal, Canada, 1977.

[35] H. Maclay and C. E. Osgood, "Hesitation phenomena in spontaneous English speech,” Word, vol. 15, no. 1, pp. 19-44, 1959.

[36] J. Rothman, "Cognitive economy, non-redundancy and typological primacy in L3 acquisition: Evidence from initial stages of L3 Romance," in Romance Languages and Linguistic 
Theory, pp. 217-247, John Benjamins, Amsterdam, Benjamins, 2012.

[37] P. Boersma and D. Weenink, "Praat version (5.3.) [42]. Doing phonetics by computer," 2014.

[38] F. Goldman-Eisler, "Pauses, clauses, sentences," Language and Speech, vol. 15, no. 2, pp. 103-113, 1972.

[39] M. Eisenstein, "Childhood bilingualism and adult language learning aptitude," Applied Psychology, vol. 29, no. 1-2, pp. 159-172, 1980.

[40] S. Modirkhamene, "The reading achievement of third language versus second language learners of English in relation to the interdependence hypothesis," International Journal of Multilingualism, vol. 3, no. 4, pp. 280-295, 2006.

[41] G. Balke-Aurell and T. Lindblad, Immigrant Children and their Languages, Department of Educational Research, University of Gothenburg, Gothenburg, Sweden, 1982.

[42] N. Nayak, N. Hansen, N. Krueger, and B. McLaughlin, "language-learning strategies in monolingual and multilingual adults," Language Learning, vol. 40, no. 2, pp. 221-244, 1990.

[43] E. Namaziandost, M. H. Razmi, S. A. Tilwani, and A. Gilakjani, "The impact of authentic materials on reading comprehension," Reading \& Writing Quarterly, 2021.

[44] M. H. Razmi, A. A. Jabbari, and A. M. Fazilatfar, "Perfectionism, self-efficacy components, and metacognitive listening strategy use: A multicategorical multiple mediation analysis," Journal of Psycholinguistic Research, vol. 49, no. 6, pp. 1047-1065, 2020. 